\title{
O Percurso Gerativo de Significação no Food Design: um estudo sobre os episódios da série Chef's Table
}

The Gifted Path of Meaning in Food Design: A study over the Chef's Table series episodes.

CHIARADIA, Bruna; Mestranda em Design; Universidade do Vale do Rio dos Sinos - UNISINOS arqbrunachiaradia@gmail.com

BENTZ, Ione Maria Ghislene Bentz; Doutora em Linguística e Semiótica; Universidade do Vale do Rio dos Sinos - UNISINOS

ioneb@unisinos.br

COSTA, Filipe Campelo Xavier da; Doutor em Administração; Universidade do Vale do Rio dos Sinos - UNISINOS

fcampelo@unisinos.br

\section{Resumo}

O presente trabalho busca compreender o percurso gerativo de significação no Food Design, através do modelo de Fontanille (2005). A partir da análise das narrativas encontradas nos seis episódios da primeira temporada de Chef's Table, série documental produzida pela Netflix que acompanha seis chefs conhecidos internacionalmente, delineamos os percursos gerativos de significação dos processos de inovação nas cozinhas da alta gastronomia.

Palavras Chave: níveis de pertinência, percurso gerativo de significação, Chef's Table; food design e gastronomia.

\begin{abstract}
The present work seeks to understand the generative path of significance in Food Design, through the model of Fontanille (2005). From the analysis of the narratives found in the six episodes of the first season of Chef's Table, a documentary series produced by Netflix that accompanies six internationally renowned chefs, we outline the sensorial paths of innovation processes in highcuisine cuisines.
\end{abstract}

Keywords: pertinence levels, sense generator path, Chef's Table; food design and gastronomy. 


\section{Introdução}

Atualmente a cultura do design encontra-se em curso de um processo transitório entre o design tradicional, nascido na cultura industrial dos primórdios do século $\mathrm{XX}$, orientado para o produto, para um design orientado para as questões sociais e ambientais. Desencadeado na virada do século XXI, quando foram trazidas à consciência da sociedade contemporânea duas questões determinantes: (a) a finitude dos recursos naturais do planeta, e (b) a partir dos avanços tecnológicos teríamos um mundo sem fronteiras, hiperconectado; que impactaram diretamente sobre a maneira como o ser humano percebe o planeta e como a sociedade se relaciona (MANZINI, 2006).

O processo projetual do design emergente se desenvolve colaborativamente e transdisciplinarmente com os stakeholders (designers, consumidor, gestores, competidores, investidores, colaboradores, fornecedores, organizações), projetando sistemas produto-serviço de forma estratégica, com intuito de gerar inovação de maneira sustentável. Consequentemente o designer assume outras atribuições, passando a projetar além do produto, os serviços e a comunicação de forma integrada, adotando papel de articulador nos diálogos entre os atores envolvidos no processo, e em constante reelaboração da forma de fazer design, além disso, deve projetar cenários prevendo futuros incertos, trabalhando além da solução de problemas, mas na elaboração de demandas (MANZINI, 2016; MERONI, 2009; ZURLO, 2010).

Ao mesmo tempo em que o design se reinventa para compreender e atender a sociedade contemporânea, disciplinas adjacentes, como o Food Design, também percebem a necessidade de evolução. A partir do momento em que é constatado que a maioria dos produtos e serviços alimentícios eram incapazes de atingir os aspectos importantes dos estilos de vida atuais, o Food Design inicia seu processo de transição de uma disciplina atuante apenas no problema estético do alimento ou das ferramentas usadas para a sua produção, para uma disciplina responsável pela identidade geral do produto e dos serviços alimentícios gastronômicos (FICHLER, 1990 apud: MERONI, 2006). Segundo a pesquisadora sobre o tema Francesca Zampollo (2016), o Food Design é definido pelo processo projetual que impulsiona à inovação de produtos, serviços ou sistemas de alimentação e consumo do alimento, das culturas dos ingredientes ao prato à mesa, passando pelo transporte, compra de ingredientes, armazenamento, preservação, preparação, apresentação, etc.

Portanto, este trabalho busca compreender o percurso gerativo de significação nos processos de inovação do Food Design, quando o alimento deixa de ter apenas o significado referente à sua função fisiológica, para ser uma experiência de consumo extraordinária. Verificando a possibilidade de aplicação desse modelo, como ferramenta de construção de significado, ou tomada de decisão, nos processos projetuais de Food Design.

A escolha da série Chef's Table para a aplicação da teoria intercorreu a partir do formato da produção, que de forma documental apresenta na primeira temporada a narrativa de seis chefes consagrados mundialmente por serem inovadores no ramo da alta gastronomia. A série retrata além do processo de preparação do alimento, ela apresenta ao espectador o percurso de vida do chef, desde sua formação, experiências, como e porque colecionam estrelas Michelin. Ademais, apresenta todo o processo envolvido na definição do menu, desde cultura e escolha dos ingredientes, o contexto territorial, os testes e experimentações, a ciência dentro da cozinha, a apresentação do prato, até a experiência prometida ao cliente.

O desenvolvimento deste estudo acontecerá num primeiro momento, com a exposição da 
teoria do modelo de percurso gerativo de significação a partir dos níveis de pertinência semiótica do Fontanille (2005) em profundidade. Num segundo momento, serão feitas as análises de percurso gerativo de significação dos processos de inovação apresentados em cada episódio da primeira temporada da série Chef's Table. Por fim, localizar pontos convergência ou divergência entre os percursos analisados, constatando a aplicação do modelo na concepção de um projeto de Food Design.

\section{Os Níveis de Pertinência Semiótica}

Fontanille (2005), em seu texto "Signos, textos, objetos, situações e formas de vida: níveis de pertinência semiótica", procura desenvolver um modelo de hierarquia e de percurso de níveis de pertinência semióticos, a fim de permitir análises do plano de conteúdo correspondentes ao percurso gerativo de significação. Não obstante, o autor assinala que a relação entre os níveis de pertinência e os planos de expressão, ainda não se apresentam com absoluta clareza, para tanto, considerando que o plano de expressão se caracteriza por uma experiência semiótica, é possível uma solução a partir do entendimento sobre como os níveis de experiência podem ser convertidos em níveis pertinentes à analise semiótica.

Através da análise de expressão, Fontanille (2005) conduz o percurso de integração dos níveis de pertinência, expondo as relações progressivas entre um nível e o seu subsequente, levando em conta seis níveis de pertinência: signos, textos-enunciados, objetos, cenas predicativas, estratégias e formas de vida:

Dos signos aos textos-enunciados: o primeiro nível diz respeito às unidades mínimas, enquanto que o segundo abrange os conjuntos significantes e textos-enunciados. A mudança de nível neste ponto, significa além do reconhecimento de figuras pertinentes, atribuir direção significante ao interpretar o material textual (verbal ou não verbal). Desta forma, transitando da experiência figurativa, para a experiência interpretativa (FONTANILLE, 2005).

Dos textos aos objetos: o texto-enunciado é um dispositivo de inscrição. Os objetos, por sua vez, são estruturas materiais compostos por uma morfologia, uma funcionalidade e uma forma identificável, destinados a uma prática um tanto quanto especializada, não necessariamente tangíveis. A mudança de nível aqui, corresponde a articulação da interpretação do texto inscrito com a manipulação do objeto, o qual pode assumir o papel de suporte do texto (superfície de inscrição), como de um dos atores da situação semiótica (participante de uma prática social), passando para a experiência dos corpos materiais (FONTANILLE, 2005).

Dos objetos às situações: "uma situação semiótica, é uma configuração heterogênea que comporta todos os elementos necessários à interpretação da significação de uma interação" (FONTANILLE, 2005, p.24). Conforme o autor, as situações podem ser experienciadas de duas formas: seja através da interação com um texto (comunicação), ou com um ou mais objetos (prática); ou através da experiência de interações paralelas de diversas práticas, sejam complementares ou concorrentes.

As situações cenas predicativas, que se referem à primeira forma de experiência da transição objetos-situações, nada mais é que a conversão de uma experiência prática para um dispositivo de expressão semiótica. Aqui, a prática se converte em um ou mais processos, representados por todas as relações entre os atores que se configurem em uma cena de prática, por exemplo a relação 
usuário x instrumento.

Enquanto que as situações-estratégias, transforma um conjunto de práticas em conjuntos significantes novos, através do planejamento de percursos e intersecções, ou de ajustamentos em tempo real. A experiência convertida em expressão, neste caso, é a experiência de conjuntura e de ajustamento de cenas predicativas práticas, onde cada cena se ajusta no espaço e no tempo em relação as outras cenas, sejam elas concomitantes ou não.

Das estratégias às formas de vida: as formas de vida representam as situações-estratégias a partir do estilo de estratégicos dos usuários, diretamente relacionado com a experiência de "caráter moral" (ethos), comportamento e identidade cultural. As formas de vida integram os níveis de pertinência antecedentes, possibilitando a composição pertinente de uma análise de culturas (FONTANILLE, 2005).

Não obstante, o autor (FONTANILLE, 2005), por meio de uma análise de conteúdo, desenvolve o percurso gerativo da significação, considerando as instâncias formais, as quais são pertinentes ao nível correspondente, e as instâncias materiais e sensíveis que substanciam o nível posterior, forma e substância respectivamente, conforme Quadro 01.

Quadro 01: Percurso gerativo de significação.

\begin{tabular}{|c|c|c|}
\hline TIPOS EXPERIÊNCIA & INSTÂNCIAS FORMAIS & INSTÂNCIAS MATERIAIS \\
\hline Figuratividade & Signos & $\begin{array}{l}\text { Propriedades sensíveis e } \\
\text { materiais das figuras }\end{array}$ \\
\hline Interpretação & Textos Enunciados & $\begin{array}{l}\text { Propriedades sensíveis e } \\
\text { materiais dos textos }\end{array}$ \\
\hline Corporeidade & Objetos & $\begin{array}{l}\text { Propriedades sensíveis e } \\
\text { materiais dos objetos }\end{array}$ \\
\hline Prática & Cenas Predicativas & $\begin{array}{l}\text { Propriedades sensíveis e } \\
\text { materiais das práticas }\end{array}$ \\
\hline Conjuntura & Estratégias & $\begin{array}{l}\text { Propriedades sensíveis e } \\
\text { materiais das estratégias }\end{array}$ \\
\hline $\begin{array}{l}\text { Ethos e } \\
\text { Comportamento }\end{array}$ & Forma de Vida & $\begin{array}{l}\text { Propriedades sensíveis e } \\
\text { materiais das formas de vida }\end{array}$ \\
\hline
\end{tabular}

Fonte: Fontanille, 2005.

Ainda, o autor afirma que o desenrolar do percurso gerativo de significação, configura-se como um exercício de sincretismo das heterogeneidades multimodais presentes em cada nível de pertinência, principalmente, se considerarmos que todas as propriedades materiais e sensíveis já estão presentes desde o primeiro nível de experiência como matérias de expressão. Isso quer dizer 
que, a cada nível a análise contempla a heterogeneidade dos dados que the correspondem, convertendo-os em conjuntos significantes para os quais, é possível propor descrições actanciais, modais, passionais, figurativas ou enunciativas.

\section{Percurso Gerativo de Significação dos episódios da série Chef's Table}

O ensaio da aplicação do modelo de percurso gerativo de significação de Fontanille (2005) ao Food Design, proposto nesse trabalho, é elaborado a partir do estudo do percurso de seis chefs, retratados na primeira temporada da série Chef's Table, produzida pela Netflix. A série documental apresenta a história desses profissionais da gastronomia através das suas práticas cotidianas, e a partir delas buscaremos compreender como esses chefs adicionam significados aos seus pratos, práticas e cozinhas, durante seus processos de inovação.

Com base na interpretação dos níveis de pertinência de Fontanille (2005) para o Food Design, as análises terão início no primeiro nível, dos signos que, por se tratarem das unidades mínimas, representarão o alimento na sua função mais primacial, suprir as necessidades fisiológicas. O segundo nível apresenta o enunciado referente ao contexto territorial e ao fator sensorial do paladar. A experiência da corporeidade acontece através das principais características dos pratos servidos pelo profissional, e desta forma a análise segue pelas suas práticas e conjunto delas, que designam sua identidade à cozinha. Por fim, o nível da forma de vida traduz o discurso principal do processo de inovação do chef em adição às experiências vividas e/ou prometidas ao consumidor.

\subsection{Massimo Bottura}

Chef italiano de Modena, na Itália, comanda o Osteria Francescana, reinventa a culinária italiana através de pratos tradicionais desconstruídos. O Quadro 02 apresenta seu percurso gerativo de significação, no cruzamento entre os tipos de experiência, as instâncias formais, e as instâncias materiais resultantes destas, e sua progressão para as instâncias formais dos níveis seguintes, e desta mesma forma se sucederá para os demais chefs.

Massimo, se apropria das receitas da mama italiana, mas a apresenta de forma que o foco esteja na compreensão dos sabores, e não na quantidade de comida. Seus pratos valorizam os ingredientes locais, contando histórias como se fossem obras de arte. Sua gastronomia é identificada como a cozinha italiana pós-moderna, que segundo ele abre portas para uma nova geração na culinária italiana. Promete ao cliente uma experiência que reinterpreta as memórias da culinária italiana tradicional. 


\begin{tabular}{|c|c|c|}
\hline TIPOS EXPERIÊNCIA & INSTÂNCIAS FORMAIS & INSTÂNCIAS MATERIAIS \\
\hline Figuratividade & $\begin{array}{l}\text { Signos } \\
\text { Alimento }\end{array}$ & $\begin{array}{l}\text { Propriedades sensíveis e } \\
\text { materiais das figuras: } \\
\text { Contexto - Modena, Itália. } \\
\text { Receitas da 'mamma'. }\end{array}$ \\
\hline Interpretação & $\begin{array}{l}\text { Textos Enunciados } \\
\text { Cozinha da "mamma" } \\
\text { Italiana }\end{array}$ & $\begin{array}{l}\text { Propriedades sensíveis e } \\
\text { materiais dos textos: } \\
\text { Assinatura do Chef aplicada às } \\
\text { receitas tradicionais. }\end{array}$ \\
\hline Corporeidade & Abjetos & $\begin{array}{l}\text { Propriedades sensíveis e } \\
\text { materiais dos objetos: } \\
\text { Foco na compreensão dos } \\
\text { sabores e não no consumo em } \\
\text { grandes quantidade. }\end{array}$ \\
\hline Prática & O prato conta a sua história. & $\begin{array}{l}\text { Propriedades sensíveis e } \\
\text { materiais das práticas: } \\
\text { Apresentação dos pratos como } \\
\text { obras de arte, que contam a } \\
\text { história dos ingredientes. }\end{array}$ \\
\hline Conjuntura & $\begin{array}{l}\text { Estratégias } \\
\text { Re-interpretação } \\
\text { de Memórias }\end{array}$ & $\begin{array}{l}\text { Propriedades sensíveis e } \\
\text { materiais das estratégias: } \\
\text { Ingredientes locais adicionados } \\
\text { a um ambiente familiar, em } \\
\text { uma nova forma de fazer a } \\
\text { culinária italiana. }\end{array}$ \\
\hline $\begin{array}{l}\text { Ethos e } \\
\text { Comportamento }\end{array}$ & $\begin{array}{l}\text { Forma de Vida } \\
\text { Cozinha Italiana } \\
\text { Pós-Moderna }\end{array}$ & $\begin{array}{l}\text { Propriedades sensíveis e } \\
\text { materiais das formas de vida: } \\
\text { Experiência prometida - comida } \\
\text { da "mamma" moderna. } \\
\text { Abertura de caminhos a nova } \\
\text { geração da cozinha italiana. }\end{array}$ \\
\hline
\end{tabular}

Fonte: adaptado pela autora de Fontanille, 2005.

\subsection{Dan Barber}

Dan Barber tem a Granja Blue Hill, no entorno de Nova lorque, onde produz todos os ingredientes servidos no seu restaurante situado em meio a paisagem dos campos. Dan afirma que o sabor do ingrediente é consequência da qualidade do pasto consumido pela vaca leiteira, portanto o trabalho dele é focado na melhoria contínua do sistema. Extensos projetos de pesquisa com profissionais de todas as áreas, vinculados a universidades e empresas, são desenvolvidos na Granja Blue Hill, com intuito de mudar a comunidade e o mundo. Segundo ele, é reinventando um jantar sofisticado para depois redefinir uma cultura do dia a dia. 
Quadro 03: Percurso gerativo de significação Dan Barber.

\begin{tabular}{|c|c|c|}
\hline TIPOS EXPERIÊNCIA & INSTÂNCIAS FORMAIS & INSTÂNCIAS MATERIAIS \\
\hline Figuratividade & $\begin{array}{l}\text { Signos } \\
\text { Alimento }\end{array}$ & $\begin{array}{l}\text { Propriedades sensíveis e } \\
\text { materiais das figuras: } \\
\text { Contexto: Granja Blue Hill, Nova } \\
\text { lorque. }\end{array}$ \\
\hline Interpretação & $\begin{array}{l}\text { Textos Enunciados } \\
\text { "Farm to Table" }\end{array}$ & $\begin{array}{l}\text { Propriedades sensíveis e } \\
\text { materiais dos textos: } \\
\text { Os ingredientes cultivados na } \\
\text { Granja Blue Hill para a mesa. }\end{array}$ \\
\hline Corporeidade & $\begin{array}{l}\text { Objetos } \\
\text { Gastronomia } \\
\text { Sazonal }\end{array}$ & $\begin{array}{l}\text { Propriedades sensíveis e } \\
\text { materiais dos objetos: } \\
\text { Todos os ingredientes são } \\
\text { cultivados e produzidos na } \\
\text { granja respeitando o tempo do } \\
\text { meio ambiente. }\end{array}$ \\
\hline Prática & Cenas Predicativas & $\begin{array}{l}\text { Propriedades sensíveis e } \\
\text { materiais das práticas: } \\
\text { A melhoria contínua do sistema } \\
\text { como um todo, do ingrediente à } \\
\text { mesa. }\end{array}$ \\
\hline Conjuntura & $\begin{array}{c}\text { Estratégias } \\
\text { Granja } \\
\text { Laboratório }\end{array}$ & $\begin{array}{l}\text { Propriedades sensiveis e } \\
\text { materiais das estratégias: } \\
\text { Pesquisa transdisciplinar } \\
\text { buscando resgatar o melhor } \\
\text { sabor do alimento. Parcerias } \\
\text { com empresas e universidades. }\end{array}$ \\
\hline $\begin{array}{l}\text { Ethos e } \\
\text { Comportamento }\end{array}$ & $\begin{array}{l}\text { Forma de Vida } \\
\text { Redefinindo a } \\
\text { Cultura Alimentar }\end{array}$ & $\begin{array}{l}\text { Propriedades sensíveis e } \\
\text { materiais das formas de vida: } \\
\text { Com ênfase na origem dos } \\
\text { alimentos, o Chef pretende } \\
\text { reinventar a cultura alimentar } \\
\text { do dia a dia, a partir da } \\
\text { reinvenção de um jantar } \\
\text { sofisticado. }\end{array}$ \\
\hline
\end{tabular}

Fonte: adaptado pela autora de Fontanille, 2005.

\subsection{Francis Mallmann}

Chef argentino que explora técnicas antigas de culinária, desenvolvendo a gastronomia primitiva da Patagônia. Francis valoriza a exuberância da natureza selvagem, de onde vem os ingredientes, e onde o tempo do fogo deve ser respeitado. $O$ trabalho da sua equipe é orquestrado pela maestranza, onde todos que estão ao redor ajudam em todo o processo. 0 importante para o Chef é a teatralidade da gastronomia, onde os sabores se misturam com o cenário e com a 
predisposição das pessoas para vivenciarem experiências singulares.

Quadro 04: Percurso gerativo de significação Francis Mallmann.

\begin{tabular}{|c|c|c|}
\hline TIPOS EXPERIÊNCIA & INSTÂNCIAS FORMAIS & INSTÂNCIAS MATERIAIS \\
\hline Figuratividade & $\begin{array}{l}\text { Signos } \\
\text { Alimento }\end{array}$ & $\begin{array}{l}\text { Propriedades sensíveis e } \\
\text { materiais das figuras: } \\
\text { Contexto - Pequena Ilha na } \\
\text { Patagônia Argentina }\end{array}$ \\
\hline Interpretação & $\begin{array}{l}\text { Textos Enunciados } \\
\text { Natureza Selvagem }\end{array}$ & $\begin{array}{l}\text { Propriedades sensíveis e } \\
\text { materiais dos textos: } \\
\text { Busca os ingredientes na } \\
\text { natureza, através da caça e da } \\
\text { pesca. }\end{array}$ \\
\hline Corporeidade & $\begin{array}{l}\text { Objetos } \\
\text { Cozinha Primitiva } \\
\text { da Patagônia }\end{array}$ & $\begin{array}{l}\text { Propriedades sensíveis e } \\
\text { materiais dos objetos: } \\
\text { Estuda e se apropria de técnicas } \\
\text { antigas e primitivas da cultura } \\
\text { culinária da Patagônia. }\end{array}$ \\
\hline Prática & Cenas Predicativas & $\begin{array}{l}\text { Propriedades sensíveis e } \\
\text { materiais das práticas: } \\
\text { Conserva alimentos na neve, } \\
\text { cozinha na fogueira, defuma na } \\
\text { lama. }\end{array}$ \\
\hline Conjuntura & $\begin{array}{l}\text { Estratégias } \\
\text { Respeitar o Tempo } \\
\text { do Alimento }\end{array}$ & $\begin{array}{l}\text { Propriedades sensíveis e } \\
\text { materiais das estratégias: } \\
\text { Respeita o tempo de cocção do } \\
\text { alimento, as regras da natureza, } \\
\text { e orquestra o trabalho em } \\
\text { equipe com maestranza. }\end{array}$ \\
\hline $\begin{array}{l}\text { Ethos e } \\
\text { Comportamento }\end{array}$ & $\begin{array}{l}\text { Forma de Vida } \\
\text { O Teatro da } \\
\text { Gatronomia }\end{array}$ & $\begin{array}{l}\text { Propriedades sensíveis e } \\
\text { materiais das formas de vida: } \\
\text { Valoriza o teatro ao redor do } \\
\text { fogo, no cenário exuberante da } \\
\text { natureza, e a socialização com a } \\
\text { experiência peculiar. }\end{array}$ \\
\hline
\end{tabular}

Fonte: adaptado pela autora de Fontanille, 2005.

\subsection{Nicki Nakayama}

Comanda o N/Naka, se destaca pela criatividade que aplica na culinária japonesa Kaiseki. A filosofia Kaiseki significa trabalhar com os melhores ingredientes possíveis vindos da natureza, respeitando a sua sazonalidade, preparando-os através de diversos tipos de cozimento. Nicki, serve menus personalizados aos clientes registrando os pratos que consomem, para que na próxima visita experimentem algo desconhecido. Segundo ela, a sua culinária traduz para quem come, a sua essência. 
Quadro 05: Percurso gerativo de significação Nicki Nakayama.

\begin{tabular}{|c|c|c|}
\hline TIPOS EXPERIÊNCIA & INSTÂNCIAS FORMAIS & INSTÂNCIAS MATERIAIS \\
\hline Figuratividade & $\begin{array}{l}\text { Signos } \\
\text { Alimento }\end{array}$ & $\begin{array}{l}\text { Propriedades sensíveis e } \\
\text { materiais das figuras: } \\
\text { Chef Japonesa em Los Angeles, } \\
\text { Estados Unidos. }\end{array}$ \\
\hline Interpretação & $\begin{array}{l}\text { Textos Enunciados } \\
\text { Cozinha Japonesa }\end{array}$ & $\begin{array}{l}\text { Propriedades sensíveis e } \\
\text { materiais dos textos: } \\
\text { Cozinha japonesa singular, } \\
\text { criativa, não tradicional. }\end{array}$ \\
\hline Corporeidade & $\begin{array}{l}\text { Objetos } \\
\text { Alimento como } \\
\text { Obra de Arte }\end{array}$ & $\begin{array}{l}\text { Propriedades sensíveis e } \\
\text { materiais dos objetos: } \\
\text { São escolhidos os melhores } \\
\text { ingredientes, e os pratos são } \\
\text { desenvolvidos como obras de } \\
\text { arte, nos mínimos detalhes. }\end{array}$ \\
\hline Prática & Cenas Predicativas & $\begin{array}{l}\text { Propriedades sensíveis e } \\
\text { materiais das práticas: } \\
\text { A criatividade da Chef é } \\
\text { adicionada à filosofia tradicional } \\
\text { japonesa que respeita a } \\
\text { sazonalidade dos ingredientes e } \\
\text { seu cozimento. }\end{array}$ \\
\hline Conjuntura & $\begin{array}{l}\text { Estratégias } \\
\text { Um menu para } \\
\text { cada convidado. }\end{array}$ & $\begin{array}{l}\text { Propriedades sensíveis e } \\
\text { materiais das estratégias: } \\
\text { Cada cliente é surpreendido } \\
\text { com um menu personalizado, } \\
\text { que não será repetido em } \\
\text { outras visitas. }\end{array}$ \\
\hline $\begin{array}{l}\text { Ethos e } \\
\text { Comportamento }\end{array}$ & $\begin{array}{c}\text { Forma de Vida } \\
\text { Personalidade } \\
\text { da Chef em cada prato. }\end{array}$ & $\begin{array}{l}\text { Propriedades sensíveis e } \\
\text { materiais das formas de vida: } \\
\text { "Minha culinária traduz para } \\
\text { quem come o que eu sou." }\end{array}$ \\
\hline
\end{tabular}

Fonte: adaptado pela autora de Fontanille, 2005.

\subsection{Ben Shewry}

Neozelandês, dono do Attica em Melbourne, desenvolve a culinária australiana a partir de ingredientes nativos. Nas noites de terça-feira, serve pratos elaborados na sua cozinha experimental com ingredientes nunca utilizados antes, e de forma passional recebe a resposta positiva ou negativa do consumidor. Ao revelar esses sabores ocultos, o grande objetivo de Ben é causar experiências gastronômicas emocionais intensas. 
Quadro 06: Percurso gerativo de significação Bem Shewry.

\begin{tabular}{|c|c|c|}
\hline TIPOS EXPERIÊNCIA & INSTÂNCIAS FORMAIS & INSTÂNCIAS MATERIAIS \\
\hline Figuratividade & $\begin{array}{l}\text { Signos } \\
\text { Alimento }\end{array}$ & $\begin{array}{l}\text { Propriedades sensíveis e } \\
\text { materiais das figuras: } \\
\text { Contexto - Melbourne Austrália. }\end{array}$ \\
\hline Interpretação & $\begin{array}{l}\text { Textos Enunciados } \\
\text { Culinária Australiana }\end{array}$ & $\begin{array}{l}\text { Propriedades sensíveis e } \\
\text { materiais dos textos: } \\
\text { Culinária australiana a partir do } \\
\text { que existe na terra. }\end{array}$ \\
\hline Corporeidade & $\begin{array}{c}\text { Objetos } \\
\text { Ingredientes Nativos }\end{array}$ & $\begin{array}{l}\text { Propriedades sensíveis e } \\
\text { materiais dos objetos: } \\
\text { Alimentos produzidos com } \\
\text { ingredientes nativos inusitados. }\end{array}$ \\
\hline Prática & Cenas Predicativas & $\begin{array}{l}\text { Propriedades sensíveis e } \\
\text { materiais das práticas: } \\
\text { Pesquisa de novos ingredientes } \\
\text { presentes na região e novas } \\
\text { formas de cozimento. }\end{array}$ \\
\hline Conjuntura & $\begin{array}{l}\text { Estratégias } \\
\text { Sabores } \\
\text { Ocultos }\end{array}$ & $\begin{array}{l}\text { Propriedades sensíveis e } \\
\text { materiais das estratégias: } \\
\text { Apropriação de sabores antes } \\
\text { desconhecidos, resultando em } \\
\text { novas experiências } \\
\text { gastronômicas. }\end{array}$ \\
\hline $\begin{array}{l}\text { Ethos e } \\
\text { Comportamento }\end{array}$ & $\begin{array}{l}\text { Forma de Vida } \\
\text { Experiências } \\
\text { Gastronômicas } \\
\text { Emocionais }\end{array}$ & $\begin{array}{l}\text { Propriedades sensíveis e } \\
\text { materiais das formas de vida: } \\
\text { Experiências gastronômicas } \\
\text { intensas e passionais. A cada } \\
\text { prato da sequência servido, } \\
\text { novos sabores conhecidos. }\end{array}$ \\
\hline
\end{tabular}

Fonte: adaptado pela autora de Fontanille, 2005.

\subsection{Magnus Nilson}

Atua no Fäviken, em Järpen na Suécia, um restaurante de 12 lugares escondido entre florestas e fiordes nórdicos, onde nada cresce durante os seis meses de inverno, utilizando ingredientes regionais, trabalhando arduamente no aprimoramento de técnicas pitorescas de conservação e preparo da comida, imprimindo sua criatividade peculiar. Seus pratos simulam a paisagem local e o ritmo do serviço é milimetricamente calculado, afim de deixar o consumidor confortável e surpreso durante sua estada no restaurante, envolvido por sua atmosfera de contos de fadas. 
Quadro 07: Percurso gerativo de significação Magnus Nilsson.

\begin{tabular}{|c|c|c|}
\hline TIPOS EXPERIÊNCIA & INSTÂNCIAS FORMAIS & INSTÂNCIAS MATERIAIS \\
\hline Figuratividade & $\begin{array}{l}\text { Signos } \\
\text { Alimento }\end{array}$ & $\begin{array}{l}\text { Propriedades sensíveis e } \\
\text { materiais das figuras: } \\
\text { Contexto - Vilarejo no interior } \\
\text { da Suécia. }\end{array}$ \\
\hline Interpretação & $\begin{array}{l}\text { Textos Enunciados } \\
\text { Um restaurante no } \\
\text { meio do nada. }\end{array}$ & $\begin{array}{l}\text { Propriedades sensíveis e } \\
\text { materiais dos textos: um } \\
\text { restaurante em meio a fiordes e } \\
\text { florestas, onde nada floresce } \\
\text { por seis meses. }\end{array}$ \\
\hline Corporeidade & $\begin{array}{l}\text { Objetos } \\
\text { Ingredientes } \\
\text { Regionais }\end{array}$ & $\begin{array}{l}\text { Propriedades sensíveis e } \\
\text { materiais dos objetos: } \\
\text { Busca por ingredientes } \\
\text { alternativos e de qualidade } \\
\text { superior. "O prato nunca será } \\
\text { melhor que o ingrediente." }\end{array}$ \\
\hline Prática & $\begin{array}{l}\text { Cenas Predicativas } \\
\text { Técnicas de Conservação } \\
\text { Ancestrais }\end{array}$ & $\begin{array}{l}\text { Propriedades sensíveis e } \\
\text { materiais das práticas: } \\
\text { Aprimoramento das técnicas de } \\
\text { conservação ancestrais. }\end{array}$ \\
\hline Conjuntura & $\begin{array}{l}\text { Estratégias } \\
\text { Criatividade } \\
\text { Constante }\end{array}$ & $\begin{array}{l}\text { Propriedades sensíveis e } \\
\text { materiais das estratégias: } \\
\text { Invenção e reinvenção de } \\
\text { técnicas culinárias. } \\
\text { Apresentação dos pratos } \\
\text { representa as paisagens locais. }\end{array}$ \\
\hline $\begin{array}{l}\text { Ethos e } \\
\text { Comportamento }\end{array}$ & $\begin{array}{l}\text { Forma de Vida } \\
\text { Como livros de } \\
\text { histórias. }\end{array}$ & $\begin{array}{l}\text { Propriedades sensíveis e } \\
\text { materiais das formas de vida: } \\
\text { A atmosfera do Fäviken permite } \\
\text { surpresas constantes ao cliente. } \\
\text { O serviço é instrumentado pelas } \\
\text { frações de segundos. }\end{array}$ \\
\hline
\end{tabular}

Fonte: adaptado pela autora de Fontanille, 2005.

\section{Conclusões}

A partir da virada do século XXI, o designer desenvolve um olhar sensível às mudanças de comportamento da sociedade e do meio ambiente, passando a atender demandas imperativas por processos projetuais sistemáticos e integrados, como agregadores de novos valores e significados, sendo inevitável a reflexão sobre suas práticas e a experimentação de novas ferramentas (MANZINI, 2016; ZURLO, 2010).

Sendo assim, a aplicação do modelo de percurso gerativo de significação do Fontanille (2005) ao Food Design, através das trajetórias de Chefs conhecidos por serem inovadores no mundo da alta gastronomia, retratados pela série online Chef's Table, ocorre na tentativa de experimentação de uma nova ferramenta a ser empregada nos processos projetuais de design de sistemas 
alimentícios e gastronômicos.

Como consequência do desenvolvimento dos percursos gerativos de significação, com base nos discursos dos profissionais estudados, é possível concluir que o emprego deste modelo na construção de significação durante o processo projetual de Food Design, é bastante pertinente. Porém, talvez ele deva ser representado de forma mais orgânica, conivente com a complexidade dos projetos sistemáticos e integrados do design emergente, visto que esta foi a dificuldade encontrada durante a elaboração do presente ensaio. Portanto, encerro este artigo, deixando como desafio, pessoal, ou para quem quer que se interesse, a construção de uma configuração representativa aperfeiçoada para o modelo de análise dos percursos gerativos de Fontanille (2005).

\section{Referências}

CHEF'S TABLE. Estados Unidos: Netflix, 2015. 1a temporada. Disponível em: https://www.netflix.com/br/title/80007945.

FONTANILLE, J. Significação e visualidade exercícios práticos. Porto Alegre: Sulina, 2005.

MANZINI, E. Design Cultures and Dialogic Design. Design Issues: Volume 32, Number 1 Winter, 2016.

MERONI, A. Strategic Design: where are we now? Reflection around the foundations of a recent discipline. In: Strategic Design Research Journal, v1, n.1, Dec 1, 2008. p.31-38.

MERONI, A. Strategic Design for the Food Sector: food-system innovation. In: 10 International Product and Service Design Symposium and Exhibition on Agricultural Industries: Olive Oil, Wine and Design Proceedings. Izmir: Izmir University of Economics, Department of Industrial Design, 2006. p.212-223.

ZAMPOLLO, F. What is Food Design? The complete overview of all Food Design sub-disciplines and how they merge. 2016. Disponível em: https://www.researchgate.net/ publication/310706545.

ZURLO, Francesco. Design Strategico. In: XXI Secolo, vol. IV, Gli spazi e le arti. Roma: Enciclopedia Treccani. 2010. 